Check for updates

Cite this: Nanoscale Adv., 2019, 1, 2580

\title{
Cupredoxin engineered upconversion nanoparticles for ratiometric luminescence sensing of $\mathrm{Cu}^{2+} \dagger$
}

\author{
Chang Liu, $\ddagger^{\mathrm{ab}}$ Yingjie Yu, $\dot{+}^{\mathrm{c}}$ Daquan Chen, (D) *a Jian Zhao, ${ }^{\mathrm{b}}$ Yang Yu, (D) Lele Li (D) *bd \\ and Yi Lu*e
}

The NIR excitation and large anti-Stokes shift of upconversion nanoparticles (UCNPs) have made them an ideal choice as biological nanoprobes. A key challenge in the field is to confer biorecognition units to UCNPs so that they can be used to probe specific targets in biological systems. While various agents have been combined with UCNPs to meet such a challenge, most studies are limited to small molecules, while biomolecules such as metalloproteins that possess much higher affinity and selectivity for metal ions have not been explored. Herein we demonstrate that fusion of zwitterion-coated UCNPs with azurin, a member of a family of redox-active copper proteins called cupredoxins that play important roles in diverse biological functions, can serve as an ideal platform for the label-free upconversion luminescence sensing of $\mathrm{Cu}^{2+}$ with a ratiometric response. The selective binding of apo-azurin with $\mathrm{Cu}^{2+}$ induces a significant absorbance at about $625 \mathrm{~nm}$, and hence decreases the red emission of the UCNPs. In contrast, the green emission of the UCNPs remains constant and acts as an internal standard reference for the ratiometric sensing of $\mathrm{Cu}^{2+}$. This approach opens a new window for the development of assays for biosensing based on a combination of specific metalloproteins with UCNPs.

Received 19th March 2019

Accepted 13th May 2019

DOI: 10.1039/c9na00168a

rsc.li/nanoscale-advances

\section{Introduction}

Lanthanide ion doped upconversion nanoparticles (UCNPs) are a new class of luminescent probes that convert NIR excitation light into shorter wavelength luminescence via multiphoton absorption and energy transfer processes, which can achieve higher-contrast optical sensing and imaging as well as deeper tissue penetration due to a suppression of autofluorescence from biomolecules and a light scattering background. ${ }^{1-4}$ In contrast to organic fluorophores and quantum dots (QDs), UCNPs exhibit neither photoblinking nor photobleaching, and their rare earth components are much less toxic than the heavy metals within QDs. ${ }^{1, \boldsymbol{b}}$ Due to these advantages, UCNPs have attracted attention from researchers in fields such as

${ }^{a}$ School of Pharmacy, Collaborative Innovation Center of Advanced Drug Delivery System and Biotech Drugs in Universities of Shandong, Yantai University, Yantai 264005, China

${ }^{b}$ CAS Key Laboratory for Biomedical Effects of Nanomaterials and Nanosafety, CAS Center for Excellence in Nanoscience, National Center for Nanoscience and Technology, Beijing 100190, China. E-mail: lilele@nanoctr.cn

'Department of Biomedical Engineering, Tufts University, Medford, MA 02155, USA

${ }^{d}$ University of Chinese Academy of Sciences, Beijing 100049, China

${ }^{e}$ Department of Chemistry, University of Illinois at Urbana-Champaign, Urbana, Illinois 61801, USA. E-mail: yi-lu@illinois.edu

$\dagger$ Electronic supplementary information (ESI) available. See DOI: 10.1039/c9na00168a

$\ddagger$ These authors contributed equally. sensing, ${ }^{2 d-g, 5-7}$ imaging, ${ }^{1 b, 3 a-d}$ and therapeutics. ${ }^{3 a, 4 b}$ Within this context, a number of UCNP-based sensor systems have been reported to detect various targets, such as metal ions, ${ }^{5}$ anions, ${ }^{6}$ and biomolecules. ${ }^{7}$ The key for the construction of such sensors is the integration of UCNPs with suitable molecules that possess specific recognition sites. However, the molecules used are mainly limited to small organic molecules. Since nature has evolved a number of tight regulatory proteins with high selectivity and sensitivity for binding of targets such as metal ions, the usage of these proteins as a sensor tool is currently attracting much interest. ${ }^{8}$ A major limitation of this design is the transformation of the binding events into an easily detectable signal. In this report, UCNPs were coupled with a unique redox protein (azurin) as a ratiometric sensor for $\mathrm{Cu}^{2+}$ sensing (Fig. 1).

As a redox-active metal ion, copper is a cofactor involved in many important biological processes, such as oxidative scavenging and respiration. ${ }^{9}$ However, at elevated concentrations, it can cause a number of severe health problems such as Menkes and Wilson's diseases, Alzheimer's disease, and liver or kidney damage. ${ }^{9 c}$ Therefore, the design of fluorescent copper sensors has become a hot topic in analytical chemistry and many effective metal ion sensors based on small organic molecules, proteins, and DNA have been reported. ${ }^{\mathbf{8}, 10}$ Despite the progress, facile on-site and real-time detection and quantification of $\mathrm{Cu}^{2+}$ in aqueous solution remain complicated due to its paramagnetic quenching effects on fluorophores. ${ }^{11}$ Alternatively, 

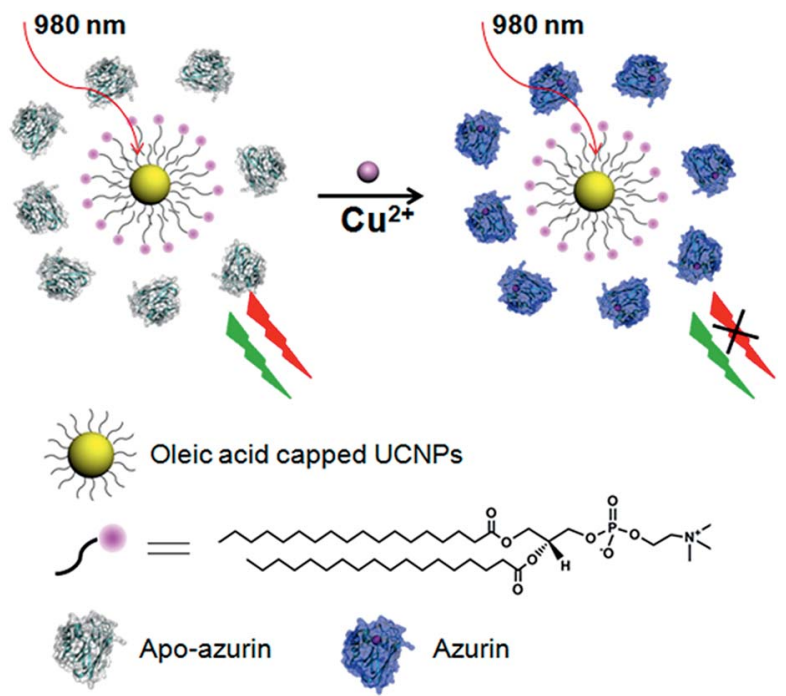

Fig. 1 Schematic illustration of the ratiometric upconversion luminescence sensing of $\mathrm{Cu}^{2+}$ based on an azurin-UCNP biosensor.

ratiometric sensors with a change in the ratio of multiple emission bands provide built-in correction for environmental effects, and thus are free of such quenching problems.

\section{Results and discussion}

Typical $\mathrm{NaYF}_{4}: 20 \% \mathrm{Yb}, 2 \% \mathrm{Er}$ UCNPs were synthesized using oleic acid as a capping ligand. ${ }^{2 a}$ Upon NIR excitation $(980 \mathrm{~nm})$, the UCNPs exhibit multiple upconversion luminescence (UCL) bands in the green and red regions, respectively (Fig. 2). Azurin is a well-characterized, $14 \mathrm{kDa}$ electron-transfer protein involved in bacterial denitrification, such as those in Pseudomonas aeruginosa. ${ }^{12}$ It has unique spectroscopic features including strong absorption $\left(>5000 \mathrm{M}^{-1} \mathrm{~cm}^{-1}\right)$ in the UV-vis absorption spectrum and a small hyperfine splitting $(\sim 50 \times$ $10^{-4} \mathrm{~cm}^{-1}$ ) for EPR..$^{12}$ In the form without $\mathrm{Cu}^{2+}$ binding, apo-

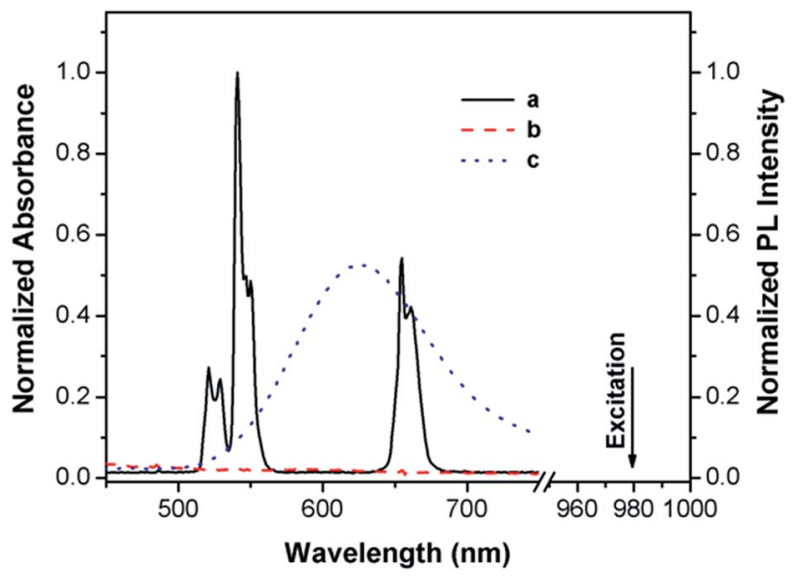

Fig. 2 UCL spectrum of DSPC-coated $\mathrm{NaYF}_{4}: 20 \% \mathrm{Yb}, 2 \% \mathrm{Er}$ (DSPCUCNPs) under excitation from a $980 \mathrm{~nm}$ laser (a), and UV-vis spectra of the protein apo-azurin in the absence (b) and presence of $\mathrm{Cu}^{2+}$ (c). azurin shows no absorption in the visible region. Apo-azurin could bind $\mathrm{Cu}^{2+}$ quite tightly through two histidines (N), a cysteine (S), and a methionine (S) (Fig. 3) and yield a significant absorbance at $625 \mathrm{~nm}$ with a molar extinction coefficient of $5600 \mathrm{M}^{-1} \mathrm{~cm}^{-1},{ }^{12}$ which ideally overlaps with the red emission band of the UCNPs. In this way, the red emission band at $654 \mathrm{~nm}$ of UCNPs is absorbed to various degrees, while its emission band at $521 \mathrm{~nm}$, by contrast, is constant and serves as an internal reference for the ratiometric sensing of $\mathrm{Cu}^{2+}$.

The $\mathrm{NaYF}_{4}: 20 \% \mathrm{Yb}, 2 \% \mathrm{Er}$ nanocrystals display a uniform hexagonal plate-like morphology with mean sizes of $\sim 60 \mathrm{~nm}$ (Fig. 4a and b and S1 $\dagger$ ). As they are prepared in organic solvents and capped with hydrophobic ligands, they are less waterdispersible and lack any functional groups for surface modification, which is a problem for biomedical application of this class of materials. ${ }^{4 i, 4 j}$ To increase their water-dispersibility and biocompatibility, a phospholipid with a zwitterionic headgroup, distearoylphosphatidylcholine (DSPC), was used to coat UCNPs with an outer surface mimicking the functionality of the cell's external membrane, since phosphorylcholine (PC) is the major hydrophilic part of the cell outer membrane. In an aqueous medium, the fatty acid chains of the phospholipid DSPC were embedded in the hydrophobic surface of the UCNPs, and the hydrophilic phosphorylcholine groups point out toward the aqueous environment, thus forming a coating with a structure analogous to the cell membrane. ${ }^{4 i}$ Representative TEM images of the resulting DSPC-UCNPs show that they remain monodisperse in water without aggregation (Fig. 4c and S1†). Highresolution TEM investigation confirms the single crystallized nanocrystals with a $\sim 4 \mathrm{~nm}$ thick uniform amorphous oleic acid/

(a)

(c)
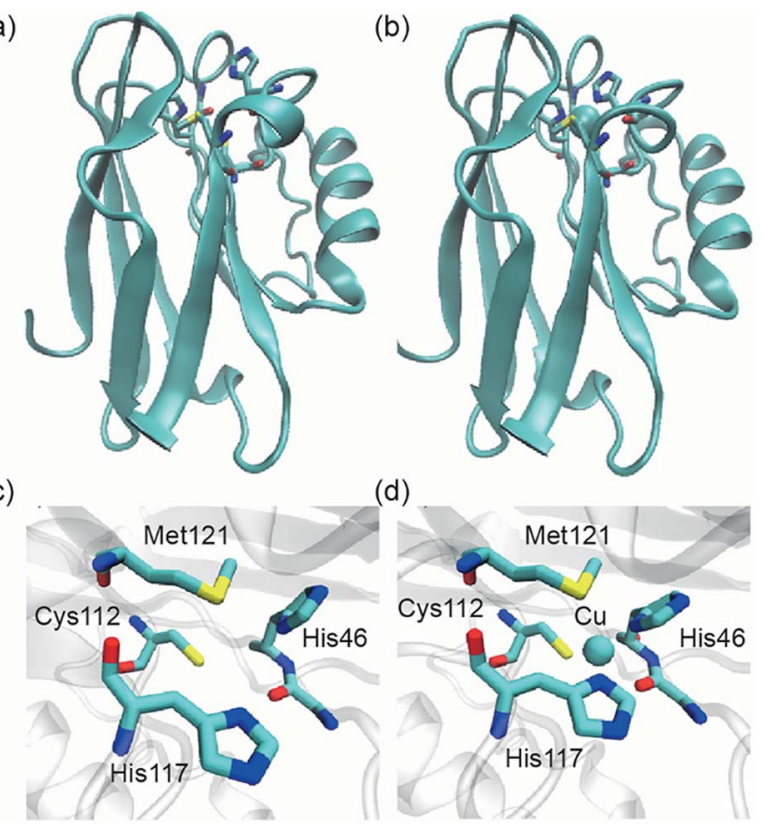

(d)

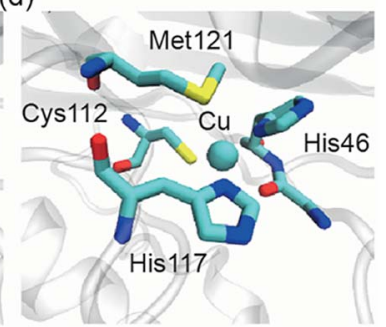

Fig. 3 ( $a$ and $b$ ) Three-dimensional illustration showing the structure of (a) apo-azurin with a $\beta$ barrel structure without $\mathrm{Cu}^{2+}$ and (b) azurin with $\mathrm{Cu}^{2+}$; the $\mathrm{Cu}^{2+}$-binding domain (c) without and (d) with $\mathrm{Cu}^{2+}$ coordination. 

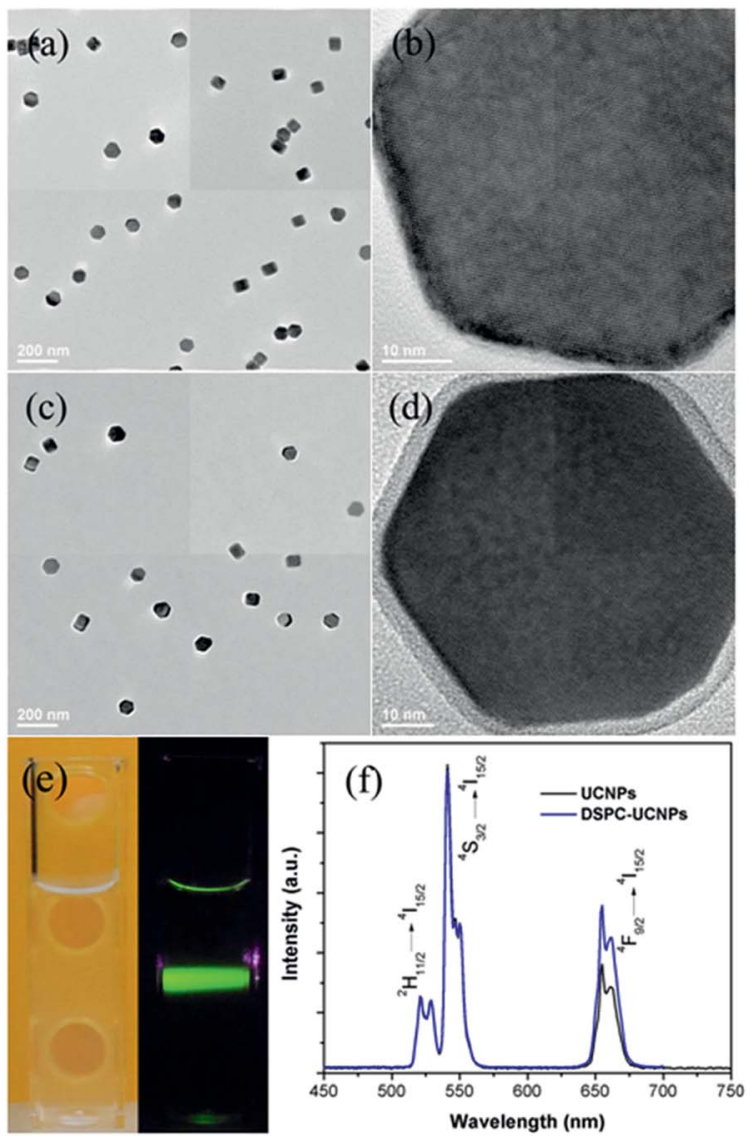

Fig. 4 TEM images of the ( $a$ and $b$ ) as-prepared and ( $c$ and $d$ ) phospholipid DSPC coated UCNPs deposited on a TEM grid from a drop of UCNP cyclohexane solution and DSPC-UCNP water solution, respectively; (e) photographs of the water solution of DSPC-UCNPs without laser illumination and the upconverted visible luminescence under continuous-wave $980 \mathrm{~nm}$ laser illumination; (f) room-temperature UCL spectra of the as-prepared UCNPs in cyclohexane and DSPC-UCNPs in water under excitation at $980 \mathrm{~nm}$.

lipid layer around it (Fig. 4d). The DSPC-UCNPs could be well dispersed in water due to the phospholipids on the outer surface. Upon continuous excitation at $980 \mathrm{~nm}$, the total luminescence of the DSPC-UCNPs in water appears yellow-green in color because of the combination of green and red emissions (Fig. 4e). The corresponding UCL spectrum of the DSPC-UCNPs in water is similar to that of the as-prepared UCNPs in cyclohexane, shown in Fig. 4f. Excited with $980 \mathrm{~nm}$, the $\mathrm{Yb}^{3+}$ ions transfer energy to $\mathrm{Er}^{3+}$ and result in the characteristic $\mathrm{Er}^{3+}$ green emission bands between 514 and $534 \mathrm{~nm}$ and between 534 and $560 \mathrm{~nm}$ due to the transitions from ${ }^{2} \mathrm{H}_{11 / 2}$ and ${ }^{4} \mathrm{~S}_{3 / 2}$ to ${ }^{4} \mathrm{I}_{15 / 2}$, respectively, and a red emission band between 635 and $680 \mathrm{~nm}$ due to the transition from ${ }^{4} \mathrm{~F}_{9 / 2}$ to ${ }^{4} \mathrm{I}_{15 / 2} \cdot{ }^{1 a}$ Furthermore, DSPCUCNPs showed prominently long-term (months) stability in water and excellent resistance to aggregation due to a balanced charge of the zwitterionic surface (Fig. S2 $\dagger$ ). Considering the cell membrane mimetic surface, high water solubility and stability, and unique optical properties of DSPC-UCNPs, it will offer an ideal platform for biosensing and bioimaging.
Upon addition of $\mathrm{Cu}^{2+}$ to a solution of apo-azurin and DSPCUCNP system, a color change from colorless to blue was observed. The intensity of the red UCL emission at $654 \mathrm{~nm}$ decreased gradually with increasing $\mathrm{Cu}^{2+}$ concentration, whereas the intensity of the green UCL band at $521 \mathrm{~nm}$ remained constant (Fig. 5a). Introduction of $\mathrm{Cu}^{2+}$ induced an increase in the spectral overlap between the red UCL emission of the UCNPs and the absorption spectrum of the metalloprotein, corresponding to decreased red UCL through the internal filter effect (IFE). ${ }^{12 b}$ Since the cell membrane mimetic coating of UCNPs could prevent the adsorption of biomolecules in a biological environment, non-specific interactions were avoided between the protein and DSPC-UCNPs, making IFE play a major role. For a control experiment, the response of DSPC-UCNPs without apo-azurin on $\mathrm{Cu}^{2+}$ was investigated, where the $\mathrm{Cu}^{2+}$-dependent UCL emission change was not observed, which further confirms the importance of the protein to the sensor design (Fig. $\mathrm{S} 3 \dagger$ ). Since the green UCL emission at $520 \mathrm{~nm}$ is independent of $\mathrm{Cu}^{2+}$, this UCL emission could serve as an internal standard reference and the ratio $\mathrm{I}_{521} / \mathrm{I}_{654}$ was used as the detection signal. As shown in Fig. $5 \mathrm{~b}$, the intensity ratios of the two UCL emissions $\left(\mathrm{I}_{521} / \mathrm{I}_{654}\right)$ gradually increase with the increasing amount of $\mathrm{Cu}^{2+}$. The signal ratios versus $\mathrm{Cu}^{2+}$ concentrations can be fitted to a linear regression equation with a detection limit of $2 \mu \mathrm{M}$, which is comparable to or lower than
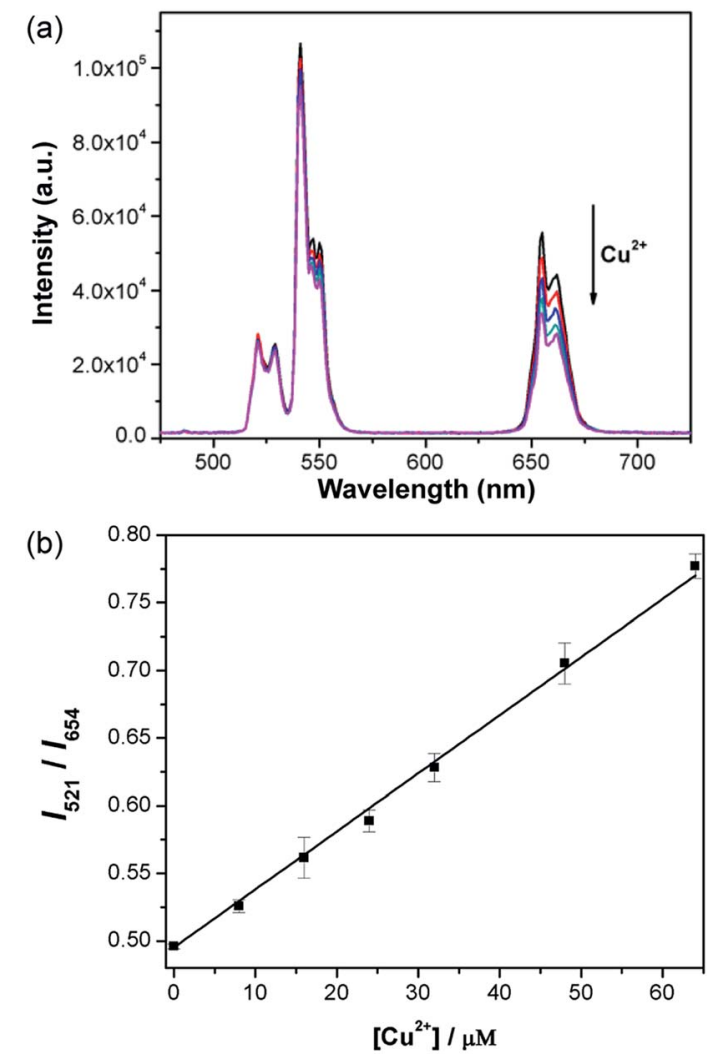

Fig. 5 (a) UCL spectra of the apo-azurin-UCNP system (under excitation from a $980 \mathrm{~nm}$ laser) in the presence of varying concentrations of $\mathrm{Cu}^{2+}$ ions; (b) the ratio $\left(\mathrm{I}_{521} / \mathrm{I}_{654}\right)$ of $\mathrm{UCL}$ intensities of the sensor system at 521 and $654 \mathrm{~nm}$ as a function of $\mathrm{Cu}^{2+}$ concentration. 
that of the previously reported methods. ${ }^{\mathbf{1 0 d}-f}$ In addition, the detection limit is well below the US Environmental Protection Agency and World Health Organization defined limits of 20 and $30 \mu \mathrm{M}$. Therefore, the detection system provides a novel way of copper detection in drinking water.

Furthermore, the time-dependent response of the system to $\mathrm{Cu}^{2+}$ was investigated. A response time of $\sim 40$ seconds was observed upon addition of $\mathrm{Cu}^{2+}$ (Fig. S4 $\dagger$ ), which suggests that the hybrid system with a quick response can be employed as a luminescent probe for real-time detection of $\mathrm{Cu}^{2+}$. For the copper-bound azurin, in its oxidised $\left(\mathrm{Cu}^{2+}\right)$ form the protein displays a strong absorption at $625 \mathrm{~nm}$ due to a ligand-to-metal charge-transfer transition involving mainly a sulfur $3 p$ orbital on the Cys112 and $\mathrm{Cu} \mathrm{d}_{x^{2}-y^{2}}$ orbital, ${ }^{12}$ and this absorption disappears when the $\mathrm{Cu}$ site is reduced into the reduced $\left(\mathrm{Cu}^{+}\right)$ form, which suggests that the UCL intensity of UCNPs can be reversibly switched based on modulation of the protein redox states. As shown in Fig. S5, $\uparrow$ binding with $\mathrm{Cu}^{2+}$ causes an obvious decrease of upconversion luminescence intensity at $654 \mathrm{~nm}$ while subsequent reduction of $\mathrm{Cu}^{2+}$ into the $\mathrm{Cu}^{+}$form through the addition of a reductant (L-ascorbate acid) could bring the luminescence back to the original level. These results indicate that the azurin/UCNP sensor system shows no response to $\mathrm{Cu}^{+}$. This optical switch observation may provide
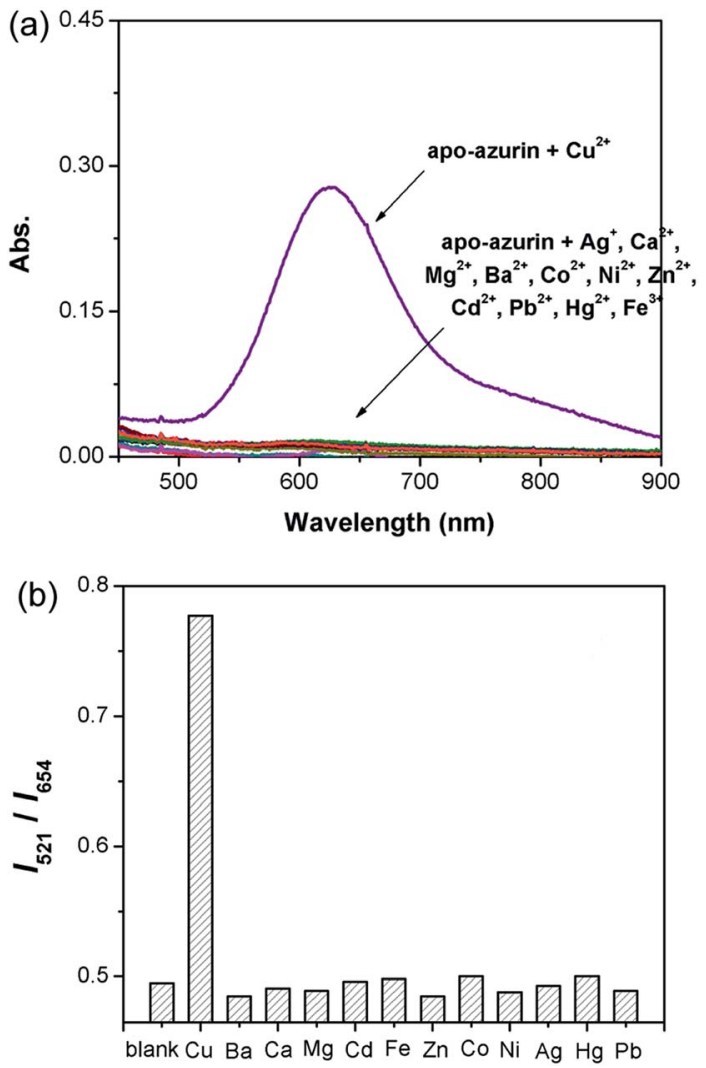

Fig. 6 (a) Changes in the absorption spectra of apo-azurin upon addition of one eq. of various metal ions; (b) the ratio $\left(I_{521} / I_{654}\right)$ of $U C L$ intensities at 521 and $654 \mathrm{~nm}$ of the sensor system (under excitation from a $980 \mathrm{~nm}$ laser) in the presence of various representative metal ions (64 $\mu \mathrm{M} \mathrm{Cu}^{2+}$ and $100 \mu \mathrm{M}$ other metal ions). a novel route for efficient nondestructive biomemory device fabrication.

High selectivity toward other biologically important cation species is necessary for a chemosensing material. The optical responses of the hybrid system were examined for other metal cations in aqueous solution. Since only $\mathrm{Cu}^{2+}$ could bind with apo-azurin and cause a drastic increase in the absorbance peak at ca. $625 \mathrm{~nm}$ from the formed metalloprotein (Fig. 6a), the introduction of $\mathrm{Cu}^{2+}$ led to significant changes in the $\mathrm{I}_{521} / \mathrm{I}_{654}$ ratio of UCL intensities, and no obvious UCL changes were observed for other metal ions, such as $\mathrm{Ag}^{+}, \mathrm{Mg}^{2+}, \mathrm{Ca}^{2+}, \mathrm{Ba}^{2+}$, $\mathrm{Co}^{2+}, \mathrm{Ni}^{2+}, \mathrm{Fe}^{3+}, \mathrm{Pb}^{2+}, \mathrm{Zn}^{2+}, \mathrm{Cd}^{2+}$, and $\mathrm{Hg}^{2+}$ (Fig. 6b). Therefore, the azurin-UCNP biosensor system described here showed highly selective ratiometric UCL sensing for $\mathrm{Cu}^{2+}$.

\section{Conclusions}

In conclusion, zwitterion-coated UCNPs were synthesized through a simple biomimetic approach. By integration of the obtained water-soluble UCNPs with a redox-active copper protein, the label-free UCL sensing of $\mathrm{Cu}^{2+}$ with a ratiometric response was demonstrated, and it possesses attractive features including NIR excitation, absence of a luminescence background, and ease of fabrication. Owing to the facile design, the method could be readily developed to build up sensing and imaging platforms for various targets by fusion of an opticalswitchable protein with UCNPs. Furthermore, since proteins have well-defined and predictable structures, and various biological activities, the protein/UCNP system offers an ideal system that should be applicable in a diverse range of areas, such as medical diagnostics, environmental monitoring, and the electronic industry. On the other hand, since zwitterionic groups on NPs will not alter the water H-bonding structure and can minimize nonspecific protein adsorption, ${ }^{\mathbf{1 3}}$ zwitterioncoated UCNPs can be useful for various biomedical applications.

\section{Experimental}

\section{Materials and reagents}

All of the chemicals used were of analytical grade and were used without further purification. Rare earth chlorides, oleic acid, and 1-octadecene were purchased from Sigma-Aldrich. Phospholipid distearoylphosphatidylcholine (DSPC) was purchased from Avanti Polar Lipids. The wild-type apo-azurin was expressed and purified as previously reported. ${ }^{12 a} \beta-\mathrm{NaYF}_{4}: \mathrm{Yb}, \mathrm{Er}$ was synthesized according to a previously reported method using rare earth chlorides as a precursor and oleic acid as a stabilizing agent. ${ }^{14}$

\section{Phospholipid coated UCNPs (DSPC-UCNPs)}

The oleic acid capped UCNPs ( $c a .0 .05 \mathrm{mmol}$ ) were dissolved in $0.5 \mathrm{~mL}$ of chloroform and then mixed with a chloroform solution ( $2 \mathrm{~mL}$ ) containing $12 \mathrm{mg}$ DSPC. The solvent was evaporated slowly, and the obtained film was heated to $75{ }^{\circ} \mathrm{C}$ for a while to completely remove chloroform. The film was hydrated with 
water $(5 \mathrm{~mL})$, and the UCNPs became water-dispersible after vigorous sonication and stirring at $75{ }^{\circ} \mathrm{C}$. The solution was centrifuged briefly and the sediment was discarded to remove large aggregates. Excess lipids were purified from DSPC-UCNPs by ultracentrifugation and washing.

\section{Detection}

In a $1 \times 1 \mathrm{~cm}$ quartz cuvette, a freshly prepared solution mixture $(2 \mathrm{~mL})$ containing $70 \mu \mathrm{M}$ apo-azurin and $100 \mu \mathrm{L}$ of the above nanoparticles in HEPES buffer $(10 \mathrm{mM}, \mathrm{pH} 7.4)$ was used for $\mathrm{Cu}^{2+}$ detection, into which a small volume $(2 \mu \mathrm{L})$ of concentrated metal stock solution was added and equilibrated for $5 \mathrm{~min}$ before the spectral measurements. To determine the selectivity of the sensor, $100 \mu \mathrm{M}$ of various metal ions $\left(\mathrm{M}^{2+}\right)$ including $\mathrm{Ag}^{+}, \mathrm{Mg}^{2+}, \mathrm{Ca}^{2+}, \mathrm{Ba}^{2+}, \mathrm{Co}^{2+}, \mathrm{Ni}^{2+}, \mathrm{Fe}^{3+}, \mathrm{Pb}^{2+}, \mathrm{Zn}^{2+}$, $\mathrm{Cd}^{2+}$, and $\mathrm{Hg}^{2+}$ was added to the sensor solution individually and the luminescence response was monitored.

\section{Instrumentation}

Transmission electron microscopy (TEM) images were taken on a JEOL 2100 Cryo transmission electron microscope with an accelerating voltage of $200 \mathrm{kV}$. Fluorescence spectra were recorded on a FluoroMax-P fluorimeter (HORIBA Jobin Yvon Inc., Edison, NJ) equipped with a commercial CW IR laser (980 $\mathrm{nm})$. UV/vis spectra were recorded on a Hewlett-Packard 8453 spectrometer.

\section{Conflicts of interest}

There are no conflicts to declare.

\section{Acknowledgements}

We acknowledge primary financial support from NSFC (No. 21822401 and 21771044) (to L. L.) and the U.S. National Institutes of Health (Grants GM124316 and MH110975) (to Y.L.) for support.

\section{Notes and references}

1 (a) F. Wang and X. Liu, Chem. Soc. Rev., 2009, 38, 976-989; (b) F. Wang, D. Banerjee, Y. Liu, X. Chen and X. Liu, Analyst, 2010, 135, 1839-1854; (c) X. Chen, D. Peng, Q. Ju and F. Wang, Chem. Soc. Rev., 2015, 44, 1318-1330; (d) J. Zhou, Q. Liu, W. Feng, Y. Sun and F. Li, Chem. Rev., 2015, 115, 395-465; (e) X. Wang, R. R. Valiev, T. Y. Ohulchanskyy, H. Ågren, C. Yang and G. Chen, Chem. Soc. Rev., 2017, 46, 4150-4167; (f) G. Tian, X. Zhang, Z. Gu and Y. Zhao, Adv. Mater., 2015, 27, 7692-7712; (g) X. Xie, Z. Li, Y. Zhang, S. Guo, A. I. Pendharkar, M. Lu, L. Huang, W. Huang and G. Han, Small, 2017, 13, 1602843.

2 (a) B. Zhou, B. Shi, D. Jin and X. Liu, Nat. Nanotechnol., 2015, 10, 924-936; (b) Y. Li, Z. Di, J. Gao, P. Cheng, C. Di, G. Zhang, B. Liu, X. Shi, L.-D. Sun, L. Li and C.-H. Yan, J. Am. Chem. Soc., 2017, 139, 13804-13810; (c) Z. G. Chen, H. L. Chen, H. Hu, M. X. Yu, F. Y. Li, Q. Zhang, Z. G. Zhou, T. Yi and
C. H. Huang, J. Am. Chem. Soc., 2008, 130, 3023-3029; (d) R. Deng, X. Xie, M. Vendrell, Y. T. Chang and X. Liu, J. Am. Chem. Soc., 2011, 133, 20168-20171; (e) Z. Li, H. Liu, H. Li, Y. H. Tsou, Y. Gao, X. Xu, W. Du, L. Wei and M. Yu, Sens. Actuators, B, 2019, 280, 94-101; (f) J. Zhao, H. Chu, Y. Zhao, Y. Lu and L. Li, J. Am. Chem. Soc., 2019, 141, 7056-7062; $(g)$ F. $\mathrm{Hu}$, B. Liu, H. Chu, C. Liu, Z. Li, D. Chen and L. Li, Nanoscale, 2019, 11, 9201-9206.

3 (a) H. Dong, S. R. Du, X. Y. Zheng, G. M. Lyu, L. D. Sun, L. D. Li, P. Z. Zhang, C. Zhang and C. Yan, Chem. Rev., 2015, 115, 10725-10815; (b) Y. Wang, G. Yang, Y. Wang, Y. Zhao, H. Jiang, Y. Han and P. Yang, Nanoscale, 2017, 9, 4759-4769; (c) Q. Qin, P. Zhang, L. Sun, S. Shi, N. Chen, H. Dong, X. Zheng, M. Li and C. Yan, Nanoscale, 2017, 9, 4660-4664; (d) J. Peng, A. Samanta, X. Zeng, S. Han, L. Yuan, X. Liu and Y.-T. Chang, Angew. Chem., Int. Ed., 2017, 56, 4165-4169; (e) Y. Wang, S. Song, J. Liu, D. Liu and H. Zhang, Angew. Chem., Int. Ed., 2015, 54, 536-540; $(f)$ J. Liu, J. Bu, W. Bu, S. Zhang, L. Pan, W. Fan, F. Chen, L. Zhou, W. Peng, K. Zhao, J. Du and J. Shi, Angew. Chem., Int. Ed., 2014, 126, 4639-4643; (g) W. Ren, Y. Zhou, S. Wen, H. He, G. Lin, D. Liu and D. Jin, Chem. Commun., 2018, 54, 7183-7186.

4 (a) R. Shi, X. Ling, X. Li, L. Zhang, M. Lu, X. Xie, L. Huang and W. Huang, Nanoscale, 2017, 9, 13739-13746; (b) D. Yang, P. A. Ma, Z. Hou, Z. Cheng, C. Li and J. Lin, Chem. Soc. Rev., 2015, 44, 1416-1448; (c) S. Chen, A. Z. Weitemier, X. Zeng, X. Liu and T. J. McHugh, Science, 2018, 359, 679684; (d) S. Han, A. Samanta, X. Xie, L. Huang and X. Liu, Adv. Mater., 2017, 29, 1700244; (e) Y. Xiao, L. Zeng, T. Xia, Z. $\mathrm{Wu}$ and Z. Liu, Angew. Chem., Int. Ed., 2015, 54, 53235327; (f) Z. Gu, L. Yan, G. Tian, S. Li, Z. Chai and Y. Zhao, Adv. Mater., 2013, 25, 3758-3779; $(g)$ N. M. Idris, M. K. G. Jayakumar, A. Bansal and Y. Zhang, Chem. Soc. Rev., 2015, 44, 1449-1478; (h) L. Li and Y. Lu, J. Am. Chem. Soc., 2015, 137, 5272-5275; (i) L. Li, R. Zhang, L. Yin, K. Zheng, W. Qin, P. R. Selvin and Y. Lu, Angew. Chem., Int. Ed., 2012, 51, 6121-6125; (j) L. Li, P. Wu, K. Hwang and Y. Lu, J. Am. Chem. Soc., 2013, 135, 2411-2414.

5 (a) Y. Liu, M. Chen, T. Cao, Y. Sun, C. Li, Q. Liu, T. Yang, L. Yao, W. Feng and F. Li, J. Am. Chem. Soc., 2013, 135, 9869-9876; (b) J. Peng, W. Xu, C. L. Teoh, S. Han, B. Kim, A. Samanta, J. C. Er, L. Wang, L. Yuan, X. Liu and Y.-T. Chang, J. Am. Chem. Soc., 2015, 137, 2336-2342; (c) Q. Su, W. Feng, D. Yang and F. Li, Acc. Chem. Res., 2017, 50, 32-40; (d) Z. Yang, K. Y. Chu, R. Feng, N. S. R. Satyavolu, M. Xiong and Y. Lu, J. Am. Chem. Soc., 2018, 140, 17656-17665.

6 (a) J. Liu, Y. Liu, Q. Liu, C. Li, L. Sun and F. Li, J. Am. Chem. Soc., 2011, 133, 15276-15279; (b) L. Zhao, J. Peng, M. Chen, Y. Liu, L. Yao, W. Feng and F. Li, ACS Appl. Mater. Interfaces, 2014, 6, 11190-11197.

7 (a) D. Tu, L. Liu, Q. Ju, Y. Liu, H. Zhu, R. Li and X. Chen, Angew. Chem., Int. Ed., 2011, 50, 6306-6310; (b) Y. Liu, S. Zhou, Z. Zhuo, R. Li, Z. Chen, M. Hong and X. Chen, Chem. Sci., 2016, 7, 5013-5019; (c) J. Zhao, J. Gao, W. Xue, Z. Di, H. Xing, Y. Lu and L. Li, J. Am. Chem. Soc., 2018, 140, 
578-581; (d) Y. Cen, Y. M. Wu, X. J. Kong, S. Wu, R. Q. Yu and X. Chu, Anal. Chem., 2014, 86, 7119-7127.

8 (a) S. V. Wegner, H. Arslan, M. Sunbul, J. Yin and C. He, J. Am. Chem. Soc., 2010, 132, 2567-2569; (b) P. Chen and C. He, J. Am. Chem. Soc., 2004, 126, 728-729.

9 (a) B. E. Kim, T. Nevitt and D. J. Thiele, Nat. Chem. Biol., 2008, 4, 176-185; (b) P. Brzezinski and R. B. Gennis, J. Bioenerg. Biomembr., 2008, 40, 521-531; (c) E. Madsen and J. D. Gitlin, Annu. Rev. Neurosci., 2007, 30, 317-337.

10 (a) J. Liu and Y. Lu, J. Am. Chem. Soc., 2007, 129, 9838-9839; (b) L. Gao, L. Li, X. Wang, P. Wu, Y. Cao, B. Liang, X. Li, Y. Lin, Y. Lu and X. Guo, Chem. Sci., 2015, 6, 2469-2473; (c) L. Shang and S. Dong, J. Mater. Chem., 2008, 18, 46364640; (d) A. Zhu, Q. Qu, X. Shao, B. Kong and Y. Tian, Angew. Chem., Int. Ed., 2012, 51, 7185-7189; (e) H. Chen,
J. Zhang, X. Liu, Y. Gao, Z. Ye and G. Li, Anal. Methods, 2014, 6, 2580-2585; (f) X. Xu, W. L. Daniel, W. Wei and C. A. Mirkin, Small, 2010, 6, 623-626.

11 (a) R. Bergonzi, L. Fabbrizzi, M. Licchelli and C. Mangano, Coord. Chem. Rev., 1998, 170, 31-46; (b) C. J. Chang, J. Jaworski, E. M. Nolan, M. Sheng and S. J. Lippard, Proc. Natl. Acad. Sci. U.S.A., 2004, 101, 1129-1134.

12 (a) N. M. Marshall, D. K. Garner, T. D. Wilson, Y. G. Gao, H. Robinson, M. J. Nilges and Y. Lu, Nature, 2009, 462, 113-116; (b) S. Tian, J. Liu, R. E. Cowley, P. Hosseinzadeh, N. M. Marshall, Y. Yu, H. Robinson, M. J. Nilges, N. J. Blackburn, E. I. Solomon and Y. Lu, Nat. Chem., 2016, 8, 670-677.

13 J. B. Schlenoff, Langmuir, 2014, 30, 9625-9636.

14 Z. Q. Li and Y. Zhang, Nanotechnology, 2008, 19, 345606. 